\title{
Analysis of Shipborne Helicopter's Guidance Error in Anti-Ship Missile Over-the-horizon Attack
}

\author{
Wang Jianguo, Yao Keming, E Qun, Wan Xinlong and Meng JinZhu \\ Dept. of Underwater Weaponry and Chemical Defence, Dalian Naval Academy, Dalian 116018, \\ China \\ wangjianguo@163.com
}

Keywords: error analysis; over-horizon attack; shipborne helicopter

\begin{abstract}
The over-the-horizon(oth) attack of anti-ship missile guided by helicopter is a common style in the attack of surface ship's missile. This paper does a research on the helicopter guiding error, and a proper method based on error transfer principle is proposed. Taking the unilateralism relative location method for example, the paper particularly analyzes the location error made by shipborne helicopter during the anti-ship missile over-horizon attack, and gives out formula for the error. The simulation is also used to validate the formula.
\end{abstract}

\section{Introduction}

With the gradual increase of anti-ship missile scope, the naval has the capability of hitting the targets beyond the horizon. But because of effects of earth's surface, the ship detection equipment can't directly detect targets beyond the horizon, So, it requires the third platform for indirect observation and to provide target information. Relay guidance is using a relay station for real-time observation and indicating the target, it provides the target information to command (or operations) platform for target location. The command (or operations) platform in relay guidance, may be the offshore(or land) command post, the offshore or onshore attack force. The relay station may be the troop or equipment from the sea to the space, such as the shore station, surface ship, aircraft or military reconnaissance satellite. Thereinto, the shipborne helicopter has the characteristics of fast, flexible, and can move along with the ship, so it becomes the responsible unique task force for relay guidance. The helicopter guidance precision is one of the important factors which influences the the combat effectiveness of the anti-ship missile oth attacking, and some scholars have done some related research ${ }^{[1-5]}$, which mainly using error ellipse super position method, but this method is very complex.

Taking the unilateralism relative location method for example, which using in the guidance for over the horizon, this paper analysis the helicopter's locaton accuracy, using the error transfer theory.

\section{Target indication and location method}

The main task of relay guidance is to provide the relevant information about the target, so the attack ship could get the target's position quickly, That is, obtained the target's orientation and distance relative to the attack ship, the helicopter relay guidance anti-ship missile oth attack diagram as shown in figure 1.

At present, the following three kinds of methods are commonly used to indicate the target: geodetic coordinate positioning, unilateralism relative location method, relative positioning unidirectional bidirectional. Because this paper uses one-way relative positioning method to the analysis of locating error, here only briefly introduces unilateralism relative location method and other two methods can be referenceed [1-3].

Unilateralism relative location method indicates the target position relative to the helicopter. It indicates position of both the target and the attack ship, and transfers these information to the attack ship, in order to get the target position for the ship. The proces, as shown in figure 2. 


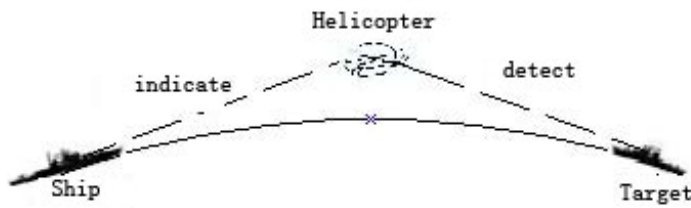

Figure 1: Helicopter relay guidance system

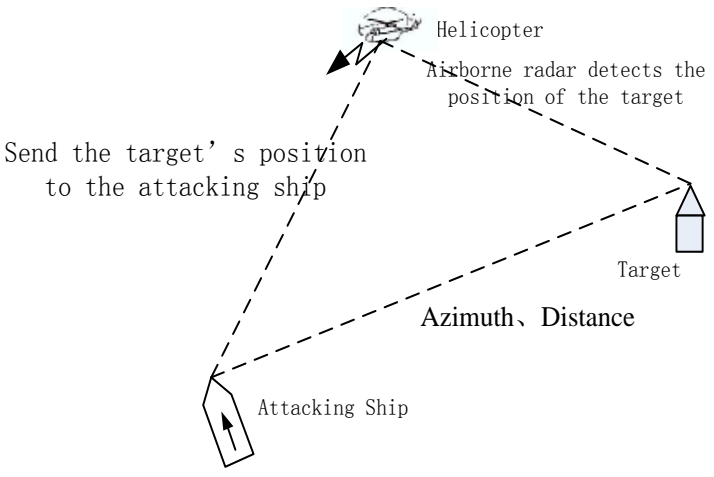

Figure 2: unilateralism relative location method

The process of unilateralism relative location method indicating and positioning as follow: the shipborne helicopter measures the distance and azimuth of the ship using the airborne radar, at the same time, it obtains the owner position from the GPS system, and sends these information to the ship. After gotting the position information from the helicopter, the attack ship computes the azimuth and distance of the target. The method has the characteristic of good ship's imperceptibility.

\section{The theory of the locating error}

In order to guidance the anti-missile oth attacking, the helicopter needs to provide not only the position information of target, such as target's azimuth and distance, but also the positioning accuracy, which is the azimuth positioning accuracy and the distance positioning accuracy.

The guidance error is relevant to the position between the helicopter, attack ship and the target, and also relevant to detection accuracy of the detection equipment . So in ordet to improving the guidance accuracy, these two aspects could be considerd: the helicopter's proper position and improving the helicopter's detection equipment precision.

In oth guidance system, error is typically expressed in root mean square error. In the process of unilateralism relative location, it only uses the airborne radar to detect target and attack ship, therefore, the guidance error is related with the airborne radar. The guidance error of anti-ship missile oth attacking process is analyzed in detail as following.

According to the principle of unilateralism relative location method, the method to obtain the position vector is shown in Figure 3.

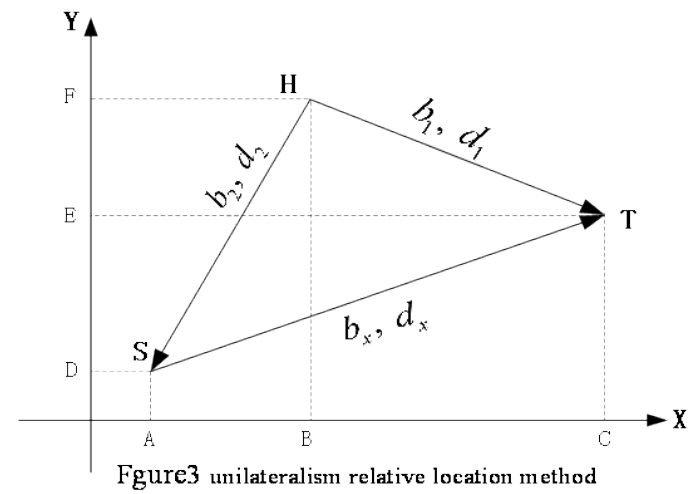

The $\mathrm{H}$ is the guidance helicopter, $\mathrm{T}$ is the target, and $\mathrm{S}$ the anti-missile attack ship, $b_{1} 、 d_{1}$ is the azimuth, distance of the target detected by the helicopter, $b_{2} 、 d_{2}$ is the azimuth, distance of the attack ship detected by the helicopter, $b_{x} 、 d_{x}$ is the wanted azimuth and distance between the attack ship and the target.

The airborne radar measurement of pitch accuracy is low, for the sake of simplicity, in this paper, only the factors of the azimuth and distance is considered. Adn the Y axis is horizontal north direction, the $\mathrm{X}$ axis is horizontal east direction.

The projection on the $\mathrm{X}$ coordinate axis: $\overrightarrow{A C}=\overrightarrow{A B}+\overrightarrow{B C}$, That is:

$$
d_{x} \cos b_{x}=-d_{2} \cos b_{2}+d_{1} \cos b_{1}
$$


By the same token, The projection on the Y coordinate axis: $\overrightarrow{D E}=\overrightarrow{D F}-\overrightarrow{E F}$, That is $d_{x} \sin b_{x}=-d_{2} \sin b_{2}+d_{1} \sin b_{1}$

According to the formula (1) and (2):

$$
\begin{array}{r}
b_{x}=\arctan \frac{d_{1} \sin b_{1}-d_{2} \sin b_{2}}{d_{1} \cos b_{1}-d_{2} \cos b_{2}} \\
d_{x}=\sqrt{d_{1}^{2}+d_{2}^{2}-2 d_{1} d_{2} \cos \left(b_{2}-b_{1}\right)}
\end{array}
$$

Differential to the formula(1) (2)

$$
\begin{aligned}
& \Delta d_{x} \cos b_{x}-d_{x} \Delta b_{x} \sin b_{x}=\Delta d_{\text {radar }}\left(\cos b_{1}-\cos b_{2}\right)-\Delta b_{\text {radar }}\left(d_{1} \sin b_{1}-d_{2} \sin b_{2}\right) \\
& \Delta d_{x} \sin b_{x}+d_{x} \Delta b_{x} \cos b_{x}=\Delta d_{\text {radar }}\left(\sin b_{1}-\sin b_{2}\right)+\Delta b_{\text {radar }}\left(d_{1} \cos b_{1}-d_{2} \cos b_{2}\right)
\end{aligned}
$$

$\Delta d_{x} 、 \Delta b_{x}$ is the distance error and azimuth error of the indicates; $\Delta d_{\text {radar }} 、 \Delta b_{\text {radar }}$ is the distance error and azimuth error of the helicopter's rada;Make $X=\left[\Delta d_{x}, \Delta b_{x}\right]^{T}$ as the helicopter oth target indication error we wanted to obtained; $Y=\left[\Delta d_{\text {radar }}, \Delta b_{\text {radar }}\right]^{T}$ as the detected error of the helicopter's radar;

Then the equation (5), and (6) can be written in the following matrix form:

$\left[\begin{array}{cc}\cos b_{x} & -d_{x} \sin b_{x} \\ \sin b_{x} & d_{x} \cos b_{x}\end{array}\right] X=\left[\begin{array}{cc}\cos b_{1}-\cos b_{2} & -\left(d_{1} \sin b_{1}-d_{2} \sin b_{2}\right) \\ \sin b_{1}-\sin b_{2} & d_{1} \cos b_{1}-d_{2} \cos b_{2}\end{array}\right] Y$

Make $M=\left[\begin{array}{cc}\cos b_{x} & -d_{x} \sin b_{x} \\ \sin b_{x} & d_{x} \cos b_{x}\end{array}\right], \quad N=\left[\begin{array}{cc}\cos b_{1}-\cos b_{2} & -\left(d_{1} \sin b_{1}-d_{2} \sin b_{2}\right) \\ \sin b_{1}-\sin b_{2} & d_{1} \cos b_{1}-d_{2} \cos b_{2}\end{array}\right]$

And Substitution the equation (3), (4) , obatained:

$$
\begin{gathered}
M X=N Y \\
M=\left[\begin{array}{cc}
\frac{d_{1} \cos b_{1}-d_{2} \cos b_{2}}{\sqrt{d_{1}^{2}+d_{2}^{2}-2 d_{1} d_{2} \cos \left(b_{2}-b_{1}\right)}} & -\left(d_{1} \sin b_{1}-d_{2} \sin b_{2}\right) \\
\frac{d_{1} \sin b_{1}-d_{2} \sin b_{2}}{\sqrt{d_{1}^{2}+d_{2}^{2}-2 d_{1} d_{2} \cos \left(b_{2}-b_{1}\right)}} & d_{1} \cos b_{1}-d_{2} \cos b_{2}
\end{array}\right] \\
N=\left[\begin{array}{cc}
\cos b_{1}-\cos b_{2} & -\left(d_{1} \sin b_{1}-d_{2} \sin b_{2}\right) \\
\sin b_{1}-\sin b_{2} & d_{1} \cos b_{1}-d_{2} \cos b_{2}
\end{array}\right]
\end{gathered}
$$

Due to the non singular of $M$, we can got:

$X=M^{-1} Y N$

In practice, the helicopter target Indication Error is commonly represented by root mean square error [5]. And radar direction finding and ranging process can be regarded as two independent processes, so

$\operatorname{cov}(Y)=\operatorname{cov}(Y, Y)=M\left[(\xi-M \xi)^{2}\right]=(D \xi)^{2}$

Namely: Y's covariance of the root mean square error of square.

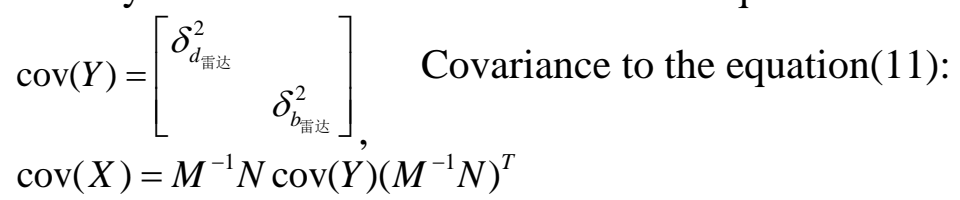

According to the error transfer theory, $\operatorname{cov}(X)$ is the request guidance precision positioning .

\section{Analysis influencing factors of the Positioning error}

From the above analysis, the measurement precision of the guidance error is relevant to the airborne radar, relative position between the helicopter and target, and the relative position between the helicopter and ship. The influence of the above factors to guide the positioning accuracy is researched as following. 


\section{Analysis of the influence on the positioning accuracy of airborne radar measurement accuracy}

Assuming the helicopter using one-way relative positioning method to guide the attack ships over the horizon attack, the basic situation is as follows: helicopter airborne radar measured target position information: $d_{1}=90 \mathrm{~km}, b_{1}=120^{\circ}$ the information of the attack ship $d_{2}=60 \mathrm{~km}, b_{2}=240^{\circ}$ 。

effect of airborne radar measurement accuracy results to guide the positioning accuracy as shown in Table 1,2.

The table 1 shows in the cases of airborne radar distance error of $150 \mathrm{~m}$, radar angle measurement error influences on guiding and positioning error; Table 2 shows in the cases of airborne radar angle error is 5 degree, radar distance measurement error influences on guiding and positioning error;

in table $1 \sim$ table 3 , range error units for the degree, distance error unit is $\mathrm{m}$, the target, assault unit of distance is $\mathrm{km}$, azimuth of units for the degree.

Table1 The effect of radar azimuth error on detection precision

\begin{tabular}{|l|l|l|l|l|l|l|}
\hline Radar azimuth error & 3 & 4 & 5 & 6 & 7 & 8 \\
\hline Positioning distance error & 258.1 & 268.3 & 284.9 & 290.2 & 292.1 & 302.8 \\
\hline $\begin{array}{l}\text { The positioning errors of } \\
\text { zimuth }\end{array}$ & 2.6 & 3.8 & 5.2 & 5.9 & 7.2 & 8.3 \\
\hline
\end{tabular}

Table 2 The effect of radar distance error on detection precision(Radar azimuth error 5 degrees )

\begin{tabular}{|c|c|c|c|c|c|c|}
\hline Radar distance error & 0 & 50 & 100 & 150 & 200 & 250 \\
\hline Positioning distance error & 0 & 86.0 & 172.1 & 258.1 & 344.1 & 430.2 \\
\hline $\begin{array}{c}\text { The positioning errors of } \\
\text { azimuth }\end{array}$ & 5.0 & 5.2 & 5.3 & 5.6 & 5.9 & 6.1 \\
\hline
\end{tabular}

The analysis of table 1, table 2, we can draw the following conclusions: the use of unilateralism relative location method of oth missile guidance attack on assault ship method, The guide positioning error of the radar performance.

Among them, the radar distance error to guide the positioning distance error has less influence than radar azimuth error on the guiding and positioning range.

Effect of assault ships, helicopters, target relative position on guidance accuracy

The basic situation is as follows: the target position information of the airborne radar detected: $d_{1}=90 \mathrm{~km}, b_{1}=120^{\circ}$, and the detection performance of airborne radar: $\delta_{d_{\text {而达 }}}=150 \mathrm{~m}, \quad \delta_{b_{\text {舿 }}}=5^{\circ}$, the location of the Assault ship(distance is $d_{1}$ and the azimuth is $b_{1}$ ) effects the guided positioning accuracy as shown in table 3, which distance between target and ship is $60 \mathrm{~km}$.

Table 3 Assault ship position (assault ship azimuth) influence on the positioning accuracy.

\begin{tabular}{|c|c|c|c|c|c|c|}
\hline Attack ship azimuth & 300 & 280 & 260 & 240 & 220 & 200 \\
\hline $\begin{array}{c}\text { Angle of } \\
\text { ship-helicopter-target }\end{array}$ & 180 & 160 & 140 & 120 & 100 & 80 \\
\hline Location distance error & 300 & 295.3 & 281.1 & 258.1 & 278.9 & 279.1 \\
\hline Location azimuth error & 10.0 & 8.2 & 7.3 & 6.1 & 6.2 & 6.3 \\
\hline
\end{tabular}

From table 3, we can draw the following conclusions: The use of one-way relative positioning of BVR missile guidance attack on assault ship method, The guide positioning error (angle and distance error) relative positions and assault ships, helicopters, the goal of the three.

In the attack helicopter - ship - targets of the three angle in 180: Guide the positioning error reaches a maximum:

For airborne radar locating error 2 times, But in the three angle at 120 degrees, The guidance error minimum

\section{Conclusion}


In this paper, shipborne helicopter guided anti-ship missile guidance accuracy of othattack is studied. Taking a unilateralism relative location method for example, the guidance error is analyzed and calculated in detail, and gives out the calculation formula of error guidance,analyzes the assault ship position, target location, airborne radar detection precision of the guide positioning errors, the results for anti-ship missile has a certain reference valuefor oth attacking.

This paper is funded by the three period of dalian naval academy 2110.

\section{Reference}

[1] Sh.Q. Dong, Zh.Q. Liu: Study on the oth target indication and target scattering region[J] Cruise missile, (2000) No.10, 39-41.

[2] Zh.J. Li, X.G. Xu: Analysis of Target Orientation Error During Over horizon Attack[J] Tacitica Missile Technology, Vol 7, (2005) No.4, 22-24.

[3] F.D. Lin, Y.Q. Zhou: The Error Computation of Over-the-horizon Guided Attack[J] Fire Control and Command Control, Vol 31, (2006) No.11, 79-81.

[4] W. Shi: Shipboard Dual-Aircraft Cooperative Location and Its Error Estimating in ASW[J] Electronics Optics \& Control, Vol 20, (2013) No.7, p. 42-47.

[5] L.Zh. Hu: Passive location, National Defence Industry Press , China,2004. 